\title{
Applying Spherical Triangle Concept in Simulator to Determine Distance and Direction of Ship
}

\author{
Damoyanto Purba \\ Nautical Study \\ Sekolah Tinggi Ilmu Pelayaran Surabaya \\ Surabaya, Indonesia \\ damoyanto.purba@gmail.com \\ Novita Vindri Harini \\ Fakultas Tarbiyah dan Keguruan \\ Universitas Islam Negeri Sunan Ampel \\ Surabaya, Indonesia \\ novitavindri19@gmail.com
}

\author{
Agus Dina Mirianto \\ Nautical Study \\ Sekolah Tinggi Ilmu Pelayaran Surabaya \\ Surabaya, Indonesia \\ agusdina02@gmail.com \\ Zainullah Zuhri \\ Fakultas Sains dan Teknologi \\ Universitas Islam Negeri Sunan Ampel \\ Surabaya, Indonesia \\ zainullah.zuhri@gmail.com
}

\begin{abstract}
Since Electronic Chart Display and Information System (ECDIS) is a very important navigator for the safety of seafaring, a cadet of Seafaring Polytechnic should learn it at class. Cadet should master how to use it properly to improve effectiveness and efficiency in seafaring. But, ECDIS only in the ship and training fee is very expensive. Seafaring Polytechnic need simulator like ECDIS, but can easily use in the class. This study reports the development of simulator that applying spherical triangle concept to determine distance and direction of the ship. $\mathrm{RnD}$ has chosen in this research. To ensure accuracy, we will compare the result of measuring with simulator and ECDIS. 51 cadets of deck department were asked to respond trial sessions of simulator. This investigation points out that the performance of this simulator tends to ECDIS with $0.072 \%$ error in measuring distance and $0.16 \%$ error in determining the direction of the ship. For the trial sessions, $85 \%$ cadets give a positive response and $87 \%$ pass the passing grade. These findings suggest that this simulator can be integrated into the marine learning process in the class. For the next research can be developed a simulator that used the map with marine traffic.
\end{abstract}

\section{Keywords-ECDIS, Simulator}

\section{INTRODUCTION}

ECDIS is a real-time navigation system that integrates data from ship's sensors (GPS, Radar, AIS, etc.) and electronic navigational charts (ENC) which complies with IMO (International Maritime Organization) regulations and can be used as an alternative to paper navigation charts [1],[2],[3],[4],[5]. The importance of ECDIS has grown increasingly on vessels, since International Maritime Organization (IMO) making the system mandatory from 2012 to 2018 [6],[7],[8]. The International Maritime Organization (IMO) is currently implementing regulations which require these systems to be installed on all commercial vessels, with the aim of completely replacing the use of paper nautical charts in the near future [8].

ECDIS makes seafaring easier and thus also safer [9]. It has many benefits such as time saving in route planning, continuously provides ship's position, generates alarms when the vessel is in the proximity of navigational hazards, preventing accidents (e.g. collisions and groundings) and protecting the ship and marine environment [2],[4],[5],[10]. Especially ECDIS functions can be used effectively in restrictive waterway areas, during periods of poor visibility, i.e. under conditions of mist and during the night.

Meanwhile, there are many potential risks in using ECDIS arising from the lack of knowledge and even negligence [2],[11]. ECDIS replaces traditional paper charts for navigation, so it requires a new kind of competence. If the navigator does not have sufficient knowledge of the use of the system, it can be a burden and a hindrance to safe navigation [8],[12]. Navigational errors can lead to catastrophic events like as loss of lives, environmental pollution, and loss of values [8]. Human error that causes accidents is one of the most significant concerns of maritime sectors. In fact, most accidents happen mainly due to human error; the lack of situational awareness and the safety culture of crews on board ships [13],[14],[15]. It is essential for navigators to learn in operating ECDIS in full and be familiar with the system in order to safe in navigation. International Maritime Organization (IMO) has recently come up with new requirements regarding ECDIS competence and proficiency [16]. Based on that fact, cadet of Seafaring Polytechnic needs to learn it early. New competency requirements in the use of ECDIS make training courses highly relevant, but training costs is very expensive. Seafaring Polytechnic need simulator like ECDIS, but can easily bring in the class. So, this study reports the development of simulator that applying spherical triangle concept to determine distance and direction of the ship.

\section{METHOD}

This research use RnD type of Borg and Gall that consists of 10 steps, those are: Research and information collecting, Planning, Develop preliminary form of product, Preliminary field testing, Main product revision, Main field testing, Operational product revision, Operational field testing, Final product revision, and Dissemination and 
implementation [17]. For practicality needs, we serve our result of research in this paper in 4 steps (Introduction, Design, Validation and Revision, and Trial and Revision).

For making sure the accuracy, this simulator (as product) will be compared with ECDIS performance. Those are: defining coordinate point of ship's position, measuring ship's mileage, and determining direction of the ship. The data of comparation will point out the accuracy of simulator quantitatively.

In trial sessions, Politeknik Pelayaran Surabaya was chosen since this polytechnic was auspices by ministry of transportation and has implemented International Maritime Organization standard curriculum in international convention STCW 1978 amendment 2010 Manila. 51 deck department cadets were asked to respond written test and questionnaire. Written test was used to measure how many cadets pass the passing grade and questionnaire was design to find out the impression on learning with simulator.

\section{RESULTS AND DISCUSSION}

The product in this research is simulator with digital web map that has function to measure distance and direction of vessel. The following steps will describe the development of the simulator:

\section{A. Step of Introduction}

Cadet are required to master skill in operating ECDIS as navigation aid in vessel. In fact, the training costs is very expensive. Marine academy need simulator like ECDIS that can be easily bring to the class for learning process. Beside it, this simulator will prove that mathematics especially spherical triangle topics is beneficial in the world of shipping. By using the simulator for teaching and learning process, cadets are expected to be more enthusiastic, motivated, and happy in study.

The simulator use phpMyAdmin as display, MySQL as database, and Google map as source chart. phpMyAdmin is a free software tool written in PHP that is intended to handle the administration of a MySQL or MariaDB database server [18]. This software can help us to perform most administration tasks, including creating a database, running queries, and adding user accounts. The data in MySQL is stored in files by different techniques, then users can get extra speed and improve the overall function of the application [19].

\section{B. Step of Design}

Design of simulator was made like ECDIS in order to make cadet familiar in operating ECDIS later in vessel. Since deck cadet as the future navigator needs to learn in using ECDIS thoroughly and be familiar with the system in order to navigate safely [13],[14],[15]. As learning media at class, simulator was expected to give stimulation of psychomotor skills for cadet. Fig. 1 is the example of initial development product:

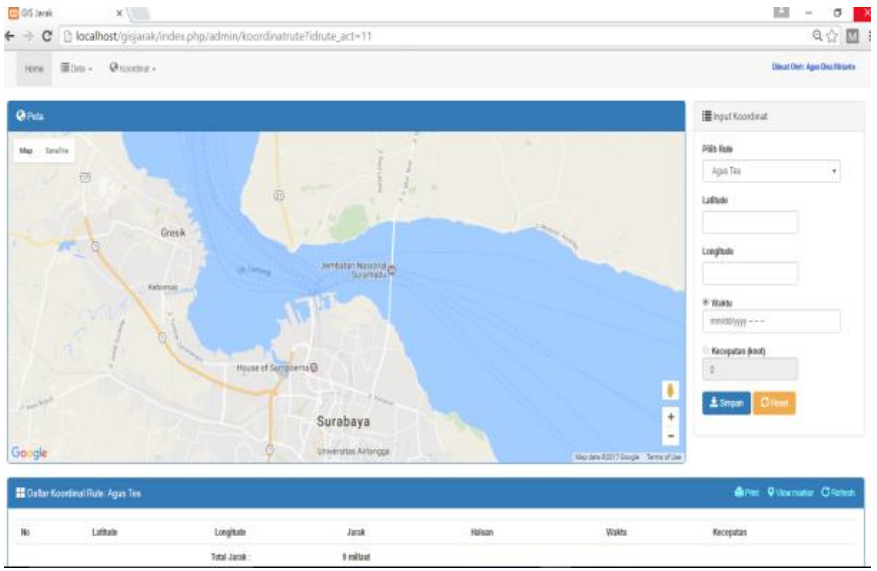

Fig. 1. Initial Product (simulator)

This simulator uses spherical triangle concept to measure distance and direction of ship. For distance of ship, we apply cosine equation in spherical triangle below [20]:

$\cos a=\cos b \cos c+\sin b \sin c \cos A$

$\cos b=\cos a \cos c+\sin a \sin c \cos B$

$\cos c=\cos a \cos b+\sin a \sin b \cos C$

For direction of ship, we apply sine equation in spherical triangle below [20]:

$\frac{\sin a}{\sin A}=\frac{\sin b}{\sin B}=\frac{\sin C}{\sin C}$

\section{Step of Validation and Revision}

Two media expertise was chosen to validate this simulator. In general, based on the results of validator 1 and validator 2, the lowest value is 3 and the highest is 4 . This means that the simulator is valid. About accuracy validation, performance of simulator will be compared with ECDIS. Input data obtained from the trip from Tanjung Mas port (Semarang) to Banjarmasin port (it can be seen in Fig. 2 and 3):

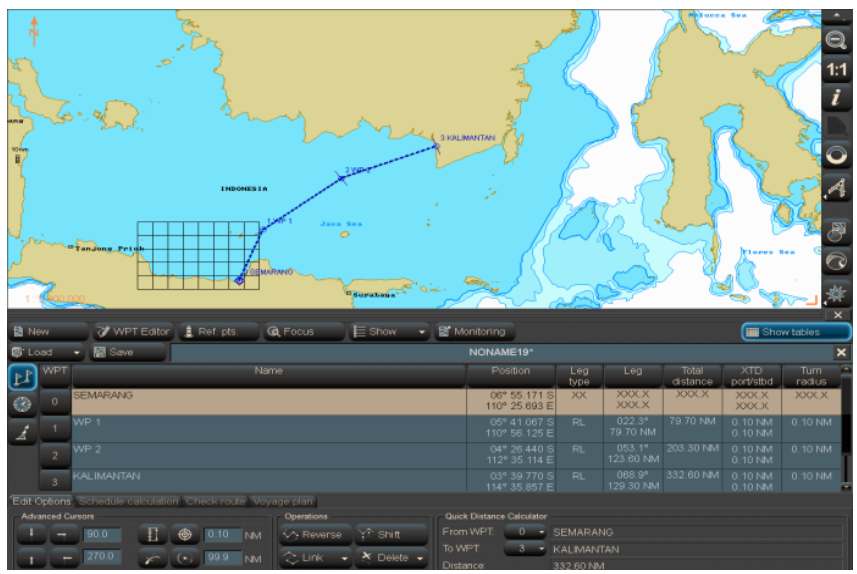

Fig. 2. Example in Using ECDIS 

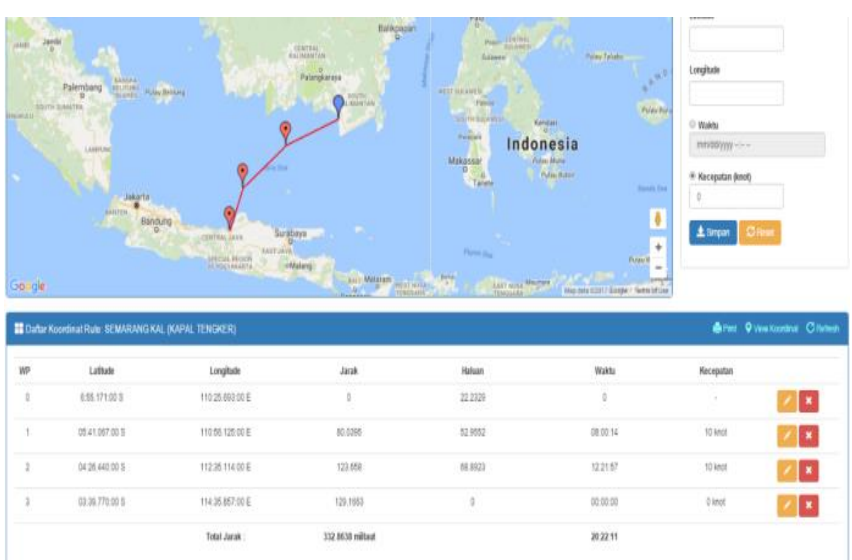

Fig. 3. Example in Using Simulator

The data about accuracy validation of simulator compared to ECDIS are presented in the following table:

TABLE 1. Measurement with Simulator vs ECDIS

\begin{tabular}{|c|r|r|r|r|r|r|r|r|}
\hline \multirow{2}{*}{$\begin{array}{c}\text { W } \\
\mathbf{p}\end{array}$} & \multicolumn{2}{|c|}{ length } & \multicolumn{2}{c|}{ ships direction } & \multicolumn{2}{c|}{ Error } & \multicolumn{2}{c|}{$\begin{array}{c}\text { error } \\
\text { presentation } \\
(\%)\end{array}$} \\
\cline { 2 - 9 } & $\begin{array}{c}E C D I \\
\boldsymbol{S}\end{array}$ & $\begin{array}{c}\text { simul } \\
\text { ator }\end{array}$ & ECDIS & $\begin{array}{c}\text { simulato } \\
\boldsymbol{r}\end{array}$ & length & $\begin{array}{c}\text { ships } \\
\text { directio } \\
\boldsymbol{n}\end{array}$ & length & $\begin{array}{c}\text { ships } \\
\text { directi } \\
\text { on }\end{array}$ \\
\hline 0 & 0 & 0 & 0 & 0 & 0 & 0 & 0,000 & 0,000 \\
\hline 1 & 79,7 & 80,03 & 22,3 & 22,23 & $-0,33$ & 0,07 & 0,397 & 0,194 \\
\hline 2 & 123,6 & 123,6 & 53,1 & 52,95 & $-0,05$ & 0,15 & 0,060 & 0,416 \\
\hline 3 & 129,3 & $\begin{array}{r}129,1 \\
6\end{array}$ & 68,9 & 68,89 & 0,14 & 0,01 & 0,168 & 0,028 \\
\hline $\begin{array}{c}\text { Av } \\
\text { era } \\
\text { ge }\end{array}$ & $\mathbf{8 3 , 1 5}$ & $\mathbf{8 3 , 2 1}$ & $\mathbf{3 6 , 0 7 5}$ & $\mathbf{3 6 , 0 1 8}$ & $\mathbf{- 0 , 0 6}$ & $\mathbf{0 , 0 5 8}$ & $\mathbf{0 , 0 7 2}$ & $\mathbf{0 , 1 6 0}$ \\
\hline
\end{tabular}

Based on the results of the accuracy of the simulator measurement compared to ECDIS, the average error distance of the ship is -0.06 and the average error direction of the ship is 0.06 . While the error percentage of the ship's mileage is $0.072 \%$ and the simulator error percentage of ship's direction is $0.16 \%$. so, it can be concluded that simulator performance in measure the distance and direction of ship is tend to ECDIS performance.

\section{Step of Trial and Revision}

User of this simulator in this time are first-level cadets (young cadets) in Deck Program at Politeknik Pelayaran Surabaya which has computer skill. They were asked to take part in trial session of learning with simulator. This stage is carried out 3 trials, namely small group trials, medium group trials, and large group trials.

From questionnaire, the positive response of cadet in small group trial was $87.5 \%$, for $85.83 \%$ for medium group trials, and $85 \%$ for large group trials. It indicates, simulator give positive impact on learning process. Besides that, data obtained from cadet learning outcomes, there were 26 cadets who passed the competency and 4 cadets did not pass. So, the completeness of the results of classical learning for cadets was $87 \%$.

\section{CONCLUSION}

This study reports the development of simulator that applying spherical triangle concept to determine distance and direction of the ship. This investigation points out that the performance of this simulator tends to ECDIS with $0.072 \%$ error in measuring distance and $0.16 \%$ error in determining the direction of the ship. For the trial sessions, $85 \%$ cadets give a positive response and $87 \%$ pass the passing grade. These findings suggest that this simulator can be integrated into the marine learning process in the class. For the next research can be developed a simulator that used the map with marine traffic.

\section{REFERENCES}

[1] Y. Dyryavyy, "Preparing for Cyber Battleships - Electronic Chart Display and Information System Security," pp. 1-10, 2014.

[2] D. Bakalar and M. B. Baggini, "Bridge officers' operational experiences with electronic chart display and information systems on ships," Pomorski zbornik, vol. 52, no. 1, pp. 49-61, 2016.

[3] S. Zhang, X. Liu, and N. Zhang, Zhang, "Exploration of the Fusion Display of ECDIS and Radar Image Information in High Latitude Sea Area," Atlantis Press, pp. 53-57, 2013 [the International Conference on Education Technology and Information System (ICETIS 2013)].

[4] L. Alexander, "Harmonising Chart and Navigation Information on ECDIS," Int. Hydrogr., review 2, no. 3, pp. 39-48, 2001.

[5] S. Bauk and R. Radlinger, "Teaching ECDIS by Camtasia Studio: Making the content more engaging," TransNav, International Journal on Marine Navigation and Safety od Sea, Transportation 7, no. 3, pp. 375-380, 2013.

[6] Choi, HyunSoo, SeWoong Oh, and SunPhill Hwang. "A Study of Development and Application on S-100 Registry." Transportation Research Procedia 21 (2017): 263-268.

[7] V. Solas, International Convention for the Safety of Life at Sea: Chapter V Safety of navigation, Regulation 19.2.10. International Maritime Organisation: London, UK, 2012.

[8] K. I. Øvergård and P. N. Smit. "The Effects of Sea Experience and Computer Confidence on Ecdis Training." J. Marit. Res., vol. 11, no. 2, pp. 25-31, 2014.

[9] C. Popescu and A. Varsami, "The use of ECDIS in modern navigation." Universitatii Maritime Constanta. Analele, vol. 11, no. 13, pp. 41-44, 2010.

[10] E. Asyali, "The Role of ECDIS in Improving Situation Awareness", 2012 [The 13th Annual General Assembly of the 1AMU].

[11] D. Brčić, S. Kos, and S. Žuškin, "Navigation with ECDIS: Choosing the proper secondary positioning source," TransNav: Inter. J. Mar. Navig. Saf. Sea Transp., vol. 9, 2015.

[12] R. O'Dwyer, “Technology not enough to prevent accidents," Digit. Sh., vol. 13, no. 3, pp. 32-6, 2012.

[13] S. B. Hong, "A study on the effects of e-navigation on reducing vessel accidents, ” 2015 [World Maritime University Dissertations 502].

[14] S. Mate (Ed.), "Navigation Special Edition", Standard Safety, June 2012.

[15] National Transportation Safety Board, "Allision of Hong KongRegistered Containership M/V Cosco Busan with the Delta Tower of the San Francisco-Oakland Bay Bridge, San Francisco, California, November 7, 2007," pp. 161, 2009.

[16] I. STCW, International Convention on Standards of Training, Certification and Watchkeeping for Seafarers, (STCW) 1978, as amended in 1995/2010, International Maritime Organisation: London, UK, 2011.

[17] W. R. Borg and M. D. Gall, Educational Research; An Introduction, $4^{\text {th }}$ ed., Longman: New York, 1983.

[18] phpMyAdmin Documentation, Release 5.1.0-dev 29 July 2019.

[19] X. Pan, W. Wu, and Y. Gu, "Study and optimization based on MySQL storage engine," In Adv. in Multimed. Softw. Eng. Comput., vol. 2, pp. 185-189. Springer, Berlin, Heidelberg, 2011. 